\title{
Androgenic potential of human fetal adrenals at the end of the first trimester
}

\author{
I Savchuk', M L Morvan², J P Antignac², K Gemzell-Danielsson³, B Le Bizec², \\ O Söder ${ }^{1}$ and $K$ Svechnikov ${ }^{1}$
}

'Department of Women's and Children's Health, Pediatric Endocrinology Unit, Karolinska Institute \& University Hospital, Stockholm, Sweden

2LUNAM Université, École Nationale Vétérinaire, Agroalimentaire et de l'Alimentation,

Nantes-Atlantique (Oniris), Laboratoire d'Étude des Résidus et Contaminants dans les Aliments (LABERCA), USC INRA 1329, Nantes, France

${ }^{3}$ Department of Obstetrics and Gynecology, Karolinska Institute \& University Hospital, Stockholm, Sweden

Correspondence

should be addressed

to K Svechnikov

Email

konstantin.svechnikov@ki.se

\begin{abstract}
The onset of steroidogenesis in human fetal adrenal glands (HFA) during the first trimester is poorly investigated. An unresolved question is the capacity of the HFA to produce potent androgen DHT via conventional and/or the backdoor pathway(s) at the end of first trimester, when androgen-responsive organs are developed. Our aim was to explore steroidogenesis and the expression of steroidogenic enzymes and transcription factors in HFA at gestational weeks (GW) 9-12 with focus on their androgenic potential. Steroids in the HFA were analyzed by gas chromatography/mass spectrometry. The expression of steroidogenic enzymes and transcription factors in the HFA at GW9-12 was investigated by qPCR, automated Western blotting and immunohistochemistry. We demonstrated that during GW9-12 HFA produced steroids of the $\Delta^{5}, \Delta^{4}$ and the backdoor pathways of the biosynthesis of DHT, though the latter was limited to production of $17 \alpha-\mathrm{OH}$-dihydroprogesterone, androsterone and androstanedione without further conversion to DHT. The only androgens identified in the HFA were testosterone and androsterone, a precursor in the biosynthesis of DHT. We also observed higher levels of CYP17A 1 but low expression of 3 $\beta$ HSD2 at GW11-12 in the HFA. Elevated levels of CYP17A1 were associated with an increased expression of SF-1 and GATA-6. Altogether, our data demonstrate that of those steroids analyzed, the only potent androgen directly produced by the HFA at GW9-12 was testosterone. The onset of steroidogenesis in the HFA is a complex process that is regulated by the coordinated action of related transcription factors.
\end{abstract}

Endocrine Connections (2017) 6, 348-359

\section{Introduction}

Steroid hormones produced by the human fetal adrenal glands (HFA) have been proposed to regulate intrauterine homeostasis and the maturation of certain organs required for extrauterine life (1). In this case, appropriate development of and hormonal production by the HFA are critical for normal fetal maturation and survival.

The HFA develop from the intermediate mesoderm and by GW7 have acquired two distinct zones, the inner http://www.endocrineconnections.org
DOI: $10.1530 /$ EC-17-0085
(C) 2017 The authors Published by Bioscientifica Ltd

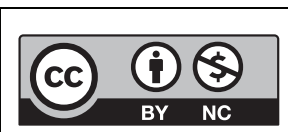

This work is licensed under a Creative Commons Attribution-NonCommercial 4.0 International License. 
fetal (FZ) and outer definitive zone (DZ) (2). In parallel, differentiation of the female and male external genitalia begins at GW7 and is completed by GW10, during which period, an overabundance of androgens can lead to abnormal male-directed development referred to as virilization (3). Deficient activity of cytochrome P450 21-hydroxylase (CYP21A2) is one defect in adrenocortical steroidogenesis well known to result in overproduction of androgens by the HFA in response to ACTH, a disorder referred to as congenital adrenal hyperplasia (4).

It has been reported that the HFA has the potential to produce testosterone from androstenedione by action of $17 \beta$ HSD5 (5), similar to that observed in the adult adrenals, where this enzyme has been found to be expressed in zona reticularis (6). It is also known that testosterone can be further converted to $5 \alpha$-dihydrotestosterone (DHT) in the target tissue such as the external genital tissue (7), and this metabolic process from cholesterol to DHT by means of testosterone is called the conventional pathway. In addition to this the frontdoor route, it has been demonstrated that 17-hydroxyprogesterone (17-OHP) can be converted to DHT in the testes of pouch young of the tammar wallaby and immature postnatal testes of rodents via an alternative 'backdoor' pathway that bypasses the conventional intermediates androstenedione and testosterone $(8,9,10)$. In this pathway, progesterone and $17 \mathrm{OH}$-progesterone are subsequently converted to dihydroprogesterone (DHP), allopregnanolone, 17-OH allopregnanolone, androsterone, androstanediol and DHT by the action of $5 \alpha$-reductase 1 (SRD5A1), CYP17A1, the family of $3 \alpha-\mathrm{HSD} 1-4$ (AKR1C1-4), 17 $\beta$ HSD3 and 17ßHSD6 (HSD17B3, HSD17B6) $(9,11)$. Recent studies have reported the presence of a backdoor pathway of DHT synthesis in newborn untreated patients with 21-hydroxylase deficiency (21-OHD), suggesting that the HFA could contribute to virilization of the female fetuses with 21-OHD via production of this potent androgen (12). In line with this, the HFA have been reported to express abundantly $A K R 1 C 1, A K R 1 C 3$ and AKR1C4 (13), suggesting that synthesis of DHT via the backdoor pathway is probable but not proven in physiological conditions by the HFA. Furthermore, recent study has proposed that DHT can be produced from androstenedione either through $5 \alpha$-androstanedione (i.e. androstenedione, $5 \alpha$-androstanedione, DHT) or through $5 \alpha$-androstanedione, androsterone and androstanediol (i.e. androstenedione, $5 \alpha$-androstanedione, androsterone, androstanediol, DHT) in the human prostate (14). Given that the HFA produce androstenedione and express many steroidogenic enzymes required for this pathway
$(5,13,15)$, such a novel pathway for the biosynthesis of DHT cannot be excluded.

One unresolved question in this context is the capacity of the HFA to produce potent androgen DHT via conventional and/or the backdoor pathway(s) at the end of the first trimester, when androgen-responsive organs are developed. Furthermore, due to limited access to appropriate material for research, little is presently known about the potential relationship between the expression of steroidogenic enzymes and of associated transcription factors by the HFA at early stages of the gland development.

Accordingly, in the present study, we carried out a comprehensive analysis of the profile of steroids produced by the HFA at the end of the first trimester. To extend our knowledge concerning the onset of steroidogenic activity of the HFA, we also explored expression of the corresponding steroidogenic enzymes and associated transcription factors during GW9-12. We found that at the end of the first trimester, the HFA have potential to produce testosterone and $5 \alpha$-reduced precursors of DHT biosynthesis but not this androgen itself. Moreover, the ontogenic expression profiles of the various steroidogenic enzymes differ and are regulated by appropriate transcription factors.

\section{Materials and methods}

\section{Ethical approval}

These experimental procedures were approved by the Regional Ethics Committee of Stockholm (EPN dnr 2014/1022-32).

\section{Human fetal adrenal collection}

HFA were obtained from aborted fetuses in connection with elective termination of pregnancy during the first trimester (9-12 weeks of gestation) at Karolinska University Hospital, Stockholm, Sweden. Fetuses were transported to the laboratory within 30 min of delivery. Gestational age was validated by ultrasound (crownrump length) and measuring fetal limb length to obtain more precise information about the age of the fetuses as described previously (16). Average value of each gestational week (GW) of the fetuses was as follows: GW9.3 \pm 0.04 $(n=9), \quad$ GW10.3 $\pm 0.06 \quad(n=10), \quad$ GW11.2 $\pm 0.05 \quad(n=14)$ and GW12.0 $\pm 0(n=5)$. The fetuses were dissected under a binocular microscope in ice-cold PBS and the HFA were removed aseptically. The HFA were isolated from

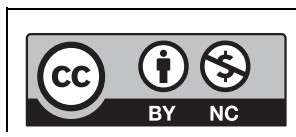

This work is licensed under a Creative Commons Attribution-NonCommercial 4.0 International License. 
individual fetuses within few minutes and immediately snap-frozen in dry ice and stored at $-85^{\circ} \mathrm{C}$ during onetwo weeks before performing analysis of steroidogenic genes expression, steroid levels assay and Western blotting or fixed overnight in neutral-buffered formaldehyde, transferred to $70 \%$ ethanol and processed for histology. Adrenals from 38 fetuses were divided into two groups (GW9-10 and GW11-12) and the sexes were pooled.

\section{Isolation of RNA and generation of CDNA}

Total RNA was extracted with the RNeasy Mini Kit (74104, Qiagen), in accordance with the manufacturer's instructions. This RNA was then pretreated with DNAse (RNase-free DNase Set, Qiagen), again as specified by the manufacturer and then quantified by spectrophotometry (BioPhotometer, Hamburg, Germany). The RNA was maintained at $-80^{\circ} \mathrm{C}$ until further processing with the iScript cDNA Synthesis Kit (Bio-Rad Laboratories) employing the manufacturer's protocol.

\section{Analysis of gene expression by qPCR}

The samples were prepared for qPCR utilizing iQ SYBR Green Supermix (170-8882, Bio-Rad Laboratories) and after determining the optimal conditions by running a temperature gradient, cycles run at $95^{\circ} \mathrm{C}$ for $10 \mathrm{~s}, 60-62^{\circ} \mathrm{C}$ for $45 \mathrm{~s}, 95^{\circ} \mathrm{C}$ for $60 \mathrm{~s}$ and $55^{\circ} \mathrm{C}$ for $60 \mathrm{~s}$, followed by performance of a melting curve from $55^{\circ} \mathrm{C}$ to $95^{\circ} \mathrm{C}$ in steps of $0.5^{\circ} \mathrm{C}$ and then maintenance at $4^{\circ} \mathrm{C}$ (iCycler iQ, BioRad Laboratories). To compensate for possible variations in RNA concentration, all values were normalized to the level of glyceraldehyde 3-phosphate dehydrogenase (GAPDH) mRNA, the product of a housekeeping gene. To monitor efficiency, negative control (RT-) was added to each qPCR assay. The $2^{-\Delta C t}$ method was applied to calculate fold changes in gene expression. An overview of the primers and running conditions employed are presented in Table 1.

\section{Automated Western blotting}

All reagents for Wes-automated Western blotting were prepared and used in accordance with the manufacturer's recommendations (ProteinSimple, San Jose, CA, USA; www.proteinsimple.com/simon.html). The HFA were lysed in CelLytic cell reagent (Sigma) and the lysates diluted with sample buffer to a protein concentration of $0.3 \mu \mathrm{g}$ in $4 \mu \mathrm{L}$ were mixed together with the $5 \mathrm{x}$ Master
Mix (DTT, fluorescence labeled marker, SDS) in a ratio 5:1 and then incubated at $95^{\circ} \mathrm{C}$ for $5 \mathrm{~min}$. The samples, the biotin-labeled protein ladder, blocking reagent, primary antibodies, HRP-conjugated secondary antibodies, chemiluminescent substrate and stacking matrices were loaded into individual wells of the sample plate. Antibodies were diluted with antibody diluent buffer. After plate loading, the separation electrophoresis and immunodetection steps took place in the capillary system and were fully automated in Wes instrument. Briefly, the capillaries first fill with separation matrix for $200 \mathrm{~s}$, and then stacking matrix for $15 \mathrm{~s}$ and finally sample for $9 \mathrm{~s}$ with vacuum injection. Separation was then performed at $375 \mathrm{~V}$ for $25 \mathrm{~min}$ in each capillary. After separation, the capillaries were exposed to UV light, activating the proprietary linking chemistry and locking the separated protein to the capillary wall. Subsequently, the matrix was removed and washed with washing buffer for three times. The capillaries were then blocked with antibody diluent to prevent non-specific binding, and target proteins were immunoprobed with primary antibodies, followed by HRP-conjugated secondary antibodies.

The 30-min incubations with primary antibodies against StAR, CYP17A1, GAPDH and CYP11A1 and 60-min incubations with SF-1, 3ßHSD2, DAX1 and GATA6 antisera were followed by incubation with HRPconjugated goat anti-rabbit secondary antibody for $30 \mathrm{~min}$. The detail information about the antibodies used is presented in Table 2 .

Luminol and peroxide (ProteinSimple) were then added to generate chemiluminescence. The digital images obtained were analyzed with the Compass software (ProteinSimple). Band densities were normalized against GAPDH and the ontogenetic expression of steroidogenic enzymes and related transcription factors were expressed as percentages of the corresponding values of GW9 values. The lane views of the expression of relevant steroidogenic enzymes and system software-generated electropherograms are shown in Supplementary Fig. 1 (see section on supplementary data given at the end of this article).

\section{GC-MS/MS analysis of steroids}

Steroids from the HFA at GW9-10 $(n=5)$ and GW11-12 $(n=7)$ were extracted twice with diethyl ether and prepared for analysis as described earlier (17). Briefly, tissue samples (from 0.5 to $15 \mathrm{mg}$ ) were ground in the presence of methanol/water 80:20 (v:v). The resulting

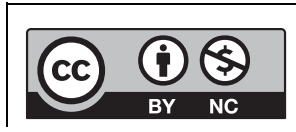

This work is licensed under a Creative Commons Attribution-NonCommercial 4.0 International License. 
Table 1 qPCR primer sequences and running conditions, bp-base pair.

\begin{tabular}{|c|c|c|c|}
\hline Oligo & Sequence & Prod. length (bp) & $\operatorname{Temp}\left({ }^{\circ} \mathrm{C}\right)$ \\
\hline GAPDH & $\begin{array}{l}\text { F: 5'-gaaggtgaaggtcggagtcaac-3' } \\
\text { R: 5'-cagagttaaaagcagccctggt-3' }\end{array}$ & 71 & $55-65$ \\
\hline CYP11A1 & $\begin{array}{l}\mathrm{F}: 5^{\prime} \text {-ctcagtcctggtcaaaggct-3' } \\
\mathrm{R}: 5^{\prime} \text {-cttctccctgtaaatcgggc-3' }\end{array}$ & 250 & 60 \\
\hline CYP17A1 & $\begin{array}{l}\text { F: 5'-ggttcgtatgggcaccaaga-3' } \\
\text { R: 5'-agagttgccatttgaggccg-3' }\end{array}$ & 111 & 60 \\
\hline GATA4 & $\begin{array}{l}\text { F: 5'-gcggaaagaggggatccaaa-3' } \\
\text { R: 5'-gaaggagctgctggtgtctt-3' }\end{array}$ & 75 & 60 \\
\hline$S F-1$ & $\begin{array}{l}\text { F: 5'-tggtgtgagggggtttctgc-3' } \\
\text { R: } 5^{\prime} \text {-aagaagcccttgcagctctca-3' }\end{array}$ & 249 & 60 \\
\hline GATA6 & $\begin{array}{l}\text { F: 5'-agaagcgcgtgccttcatc-3' } \\
\text { R: } 5^{\prime} \text {-catagcaagtggtctgggca-3' }\end{array}$ & 158 & 60 \\
\hline$C E B P B$ & $\begin{array}{l}\text { F: 5'-gcacagcgacgagtacaaga-3' } \\
\text { R: 5'-tgcttgaacaagttccgcag-3' }\end{array}$ & 192 & 60 \\
\hline MRAP & $\begin{array}{l}\text { F: 5'-agatgaggaacagccccaag-3' } \\
\text { R: 5'-gggtcagttcccagaggaga-3' }\end{array}$ & 243 & 60 \\
\hline SULT2A1 & $\begin{array}{l}\text { F: } 5^{\prime} \text {-tcagttccaaggccaaggtg-3' } \\
\text { R: } 5^{\prime} \text {-tcctgtgtcctgtttcagctc- } 3^{\prime}\end{array}$ & 248 & 60 \\
\hline$A K R 1 C 4$ & $\begin{array}{l}\text { F: 5'-gaggaacagagctgtgtagaggtcacc-3' } \\
\text { R: 5'-tgaaagaaagtgcaccaaagct-3' }\end{array}$ & 185 & 60 \\
\hline$A K R 1 D 1$ & $\begin{array}{l}\text { F: 5'-cttgggaggttgagtgccat-3' } \\
\text { R: 5'-cgctggatgttgaaacgcaa-3' }\end{array}$ & 226 & 60 \\
\hline$S P 1$ & $\begin{array}{l}\text { F: 5'-cagcgtccgcgtttttcc-3' } \\
\text { R: 5'-tgatcttggtcgctcatggt-3' }\end{array}$ & 93 & 60 \\
\hline$M C 2 R$ & $\begin{array}{l}\text { F: 5'-gcacagttcatgtgggatga-3' } \\
\text { R: } 5^{\prime} \text {-cacacgaggacagtcggaat-3' }\end{array}$ & 232 & 60 \\
\hline HSD17B3 & $\begin{array}{l}\text { F: 5'-caccggatgaaatccagagcc-3' } \\
\text { R: 5'-gacagcatatggggtcagcac-3' }\end{array}$ & 253 & 60 \\
\hline STAR & $\begin{array}{l}\text { F: 5'-tgggagctcctacagacaca-3' } \\
\text { R: } 5^{\prime} \text {-ttccagccgagaaccgagta-3' }\end{array}$ & 163 & 60 \\
\hline$A K R 1 C 3$ & $\begin{array}{l}\text { F: 5'-aagaagtaaagctttggaggtcaca-3' } \\
\text { R: } 5^{\prime} \text {-cgatgaaaagtggaccaaagct-3' }\end{array}$ & 183 & 60 \\
\hline$D A X-1$ & $\begin{array}{l}\text { F: 5'-tgctctttaacccggacggagtg-3' } \\
\text { R: } 5^{\prime} \text {-gcgtcatcctggtgtgttca-3' }\end{array}$ & 102 & 60 \\
\hline COUP-TFII & $\begin{array}{l}\text { F: 5'-tcctgttcacctcagatgcc-3' } \\
\text { R: } 5^{\prime}-\text { ctttccgaatctcgtcggct-3' }\end{array}$ & 131 & 60 \\
\hline$L R H-1$ & $\begin{array}{l}\text { F: 5'-tcctggttactgggcaacaa-3' } \\
\text { R: 5'-gaggttgttgagggtggctc-3' }\end{array}$ & 71 & 60 \\
\hline HSD3B2 & $\begin{array}{l}\text { F: 5'-tctaagttacgccctcttctgg-3' } \\
\text { R: } 5^{\prime} \text {-ttgtccaaggccctgatctc- } 3^{\prime}\end{array}$ & 207 & 60 \\
\hline$P O R$ & $\begin{array}{l}\text { F: 5'-tgccagcgtttcatgatcaac-3' } \\
\text { R: 5'-gagacccacgatgagcgaaa-3' }\end{array}$ & 132 & 60 \\
\hline CYB5A & $\begin{array}{l}\text { F: 5'-ggagctccatccagaaactct-3' } \\
\text { R: } 5^{\prime} \text {-ttcctgcgctgacttctgag-3' }\end{array}$ & 157 & 60 \\
\hline$A K R 1 C 2$ & $\begin{array}{l}F: 5^{\prime} \text {-taaaagtaaagctctagaggccgt-3' } \\
\text { R: 5'-cgatgggaattgctccaaagctt-3' }\end{array}$ & 183 & 60 \\
\hline SRD5A1 & $\begin{array}{l}\text { F: 5'-tctgatgcgaggaggaaagc-3' } \\
\text { R: 5'-catgcccgttaaccacaagc-3' }\end{array}$ & 175 & 60 \\
\hline
\end{tabular}

mash was transferred in glass tubes, and the methanol layer was evaporated under $\mathrm{N}_{2}$ stream. Then, an enzymatic deconjugation was performed for hydrolysis of glucuronide and sulfate forms by $\beta$-glucuronidase and arylsulfatase, respectively. The deconjugation was operated overnight at $37^{\circ} \mathrm{C}$. All total (free +deconjugated) steroids were then extracted twice with diethyl ether. A liquid/liquid partitioning with pentane was used to separate androgens/progestogens from estrogens, and the two resulting fractions were finally submitted to a further purification through silica $(\mathrm{SiOH})$ solid-phase extraction cartridges.

Detection and quantification of androgens and estrogens were performed on a Scion 436 gas chromatograph coupled to a Scion TQ triple quadrupole mass spectrometer (Bruker, Fremont, CA, USA) as described

$$
\begin{array}{|lr}
\text { http://www.endocrineconnections.org } & \text { ○ } 2017 \text { The authors } \\
\text { DOI: } 10.1530 / \text { EC-17-0085 } & \text { Published by Bioscientifica Ltd }
\end{array}
$$


Table 2 List of antibodies used in the study.

\begin{tabular}{|c|c|}
\hline Peptide/protein target & Name of antibody \\
\hline SF-1 & NR5A1 \\
\hline DAX1 & DAX1/NR0B1 \\
\hline CYP17A1 & $\begin{array}{l}\text { Anti-cytochrome P450 17A1 antibody } \\
\text { (EPR6293) }\end{array}$ \\
\hline CYP11A1 & Anti-CYP11A1 antibody \\
\hline GATA-6 & GATA-6 (H-92) \\
\hline $3 \beta-H S D$ & $3 \beta-H S D(H-143)$ \\
\hline StAR & StAR (FL-285) \\
\hline GAPDH & GAPDH (FL-335) \\
\hline $5 \alpha \mathrm{R} 1$ & $5 \alpha$ RED1(H-105) \\
\hline AKR1C3 & $\begin{array}{l}\text { Human Aldo-keto Reductase } \\
\text { 1C3/AKR1C3 }\end{array}$ \\
\hline $5 \beta R 1$ & AKR1D1 \\
\hline AKR1C1/AKR1C2 & $\begin{array}{l}\text { Anti-AKR1C1/AKR1C2 antibody } \\
\text {-C-terminal }\end{array}$ \\
\hline
\end{tabular}

\begin{tabular}{l} 
Manufacturer, catalog no. or \\
name of source \\
\hline NovusBiologicals, NBP1-52823 \\
NovusBiologicals, NBP1-32832 \\
Abcam, ab125022 \\
Abcam, ab175408 \\
Santa Cruz, sc-9055 \\
Santa Cruz, sc-28206 \\
Santa Cruz, sc-25806 \\
Santa Cruz, sc-25778 \\
Santa Cruz, sc-20658 \\
R\&D Systems, MAB7678 \\
Thermo Fisher Scientific, \\
PA5-28963 \\
Abcam, ab170613
\end{tabular}

Species raised in monoclonal or polyclonal

Rabbit polyclonal

Rabbit polyclonal

Rabbit monoclonal

Rabbit polyclonal

Rabbit polyclonal

Rabbit polyclonal

Rabbit polyclonal

Rabbit polyclonal

Rabbit polyclonal

Mouse monoclonal

Rabbit polyclonal

Rabbit polyclonal

\begin{tabular}{c}
$\begin{array}{c}\text { Dilution } \\
\text { used }\end{array}$ \\
\hline $1: 50$ \\
$1: 50$ \\
$1: 50$ \\
$1: 300$ \\
$1: 25$ \\
$1: 25$ \\
$1: 100$ \\
$1: 150$ \\
$1: 100$ \\
$1: 100$ \\
$1: 100$ \\
$1: 100$
\end{tabular}

without $0.01 \%$ Tween 20 (P/N P1379, Sigma Aldrich), the previously $(17,18)$. The steroids assayed, all involved in the biosynthesis of androgens and estrogens via the $\Delta^{4}, \Delta^{5}$ and backdoor pathways for DHT synthesis were as follows: pregnenolone, progesterone, 17-hydroxypregnenolone, 17-hydroxyprogesterone, androstenedione, DHEA, $17 \beta$-testosterone, $17 \alpha$-testosterone, DHT, androsterone, etiocholanolone, $\quad 17 \alpha$-hydroxydihydroprogesterone, $5 \alpha$-androstanedione, $\quad 17 \alpha \mathrm{OH}$-allopregnanolone, allopregnanolone, androstanedione, androstanediol, 5 -androstene-3 $\alpha, 17 \beta$-diol, $\quad 5$-androstene-3 $\beta, 17 \alpha$ diol, $5 \alpha$-androstane-3 $\beta-17 \alpha$-diol, epiandrosterone, 5 -androstene- $3 \beta, 17 \beta$-diol, $5 \alpha$-androstane-3 $\beta$ - $17 \beta$-diol and $17 \beta$-estradiol. The coefficients of determination $\left(R^{2}\right)$ of the calibration curves performed for each batch of analysis were higher than 0.99 . The inter-day repeatability was lower than $10 \%$ for a majority of substances, and globally lower than 20\% (Supplementary Table 1).

\section{Immunohistochemical analysis}

Paraffin-embedded fetal adrenal tissue was cut to a thickness of $5 \mu \mathrm{m}$ and mounted on microscope slides (P/N10143352, Superfrost Plus, Thermo Scientific) and placed at $60^{\circ} \mathrm{C}$ for $40 \mathrm{~min}$ in the oven. Tissue sections were dewaxed with xylene (P/N 02080, HistoLab, Gothenburg, Sweden) for $20 \mathrm{~min}$ and then rehydrated in graded ethanol (99.6, 96 and 70\%). Antigen retrieval in $0.01 \mathrm{M}$ citrate buffer ( $\mathrm{pH}$ 6.0) for $20 \mathrm{~min}$ in a water bath was used for all slides.

Samples were incubated with $3 \% \mathrm{H}_{2} \mathrm{O}_{2}$ in $96 \%$ methanol for $10 \mathrm{~min}$ at RT for non-specific endogenous peroxidase blocking. After washing with PBS with or

\begin{tabular}{|lr}
\hline http://www.endocrineconnections.org & ○ 2017 The authors \\
DOI: 10.1530/EC-17-0085 & Published by Bioscientifica Ltd
\end{tabular}

sections were treated with a mixture of $3 \%$ goat serum and $1 \%$ bovine serum albumin (BSA) in PBS for $60 \mathrm{~min}$ at RT to avoid non-specific binding. Slides were subsequently incubated with primary mouse monoclonal antibody to $17 \beta$ HSD5 and rabbit polyclonal antibodies against

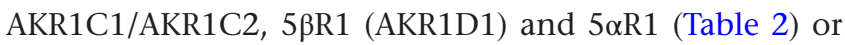
unspecific IgGs (for negative control) dissolved in 3\% goat serum in PBS overnight at $4^{\circ} \mathrm{C}$. After washing with PBS and 0.01\% Tween 20, the slides were incubated with biotinylated secondary antibody (ab64256, Abcam), and then with avidin-biotin-peroxidase complex prepared using Vectastain ABC kit (PK-6100, Vector Laboratories, Burlingame, CA, USA) for $60 \mathrm{~min}$ at RT. Finally, the slides were stained with DAB (SK-4105, Vector Laboratories) for $20-40 \mathrm{~s}$ at RT, washed twice with $\mathrm{H}_{2} \mathrm{O}$, counterstained with Hämalaun solution (Merck), rinsed for five min with running tap water, dehydrated with gradually increasing concentrations of ethanol, cleared with xylene and mounted with cover glass. IgG-negative sections exposed to non-immune rabbit and mouse serum in the absence of primary antibody were included in all immunohistochemistry runs and showed no positive immunostaining.

\section{Statistical analyses}

Differences between values were analyzed for statistical significance with Student's $t$-test for pairwise comparison and by the one-way analysis of variance (ANOVA) for multi comparison followed by Student-Newman-Keuls analysis or Dunn's analysis if the normality test failed

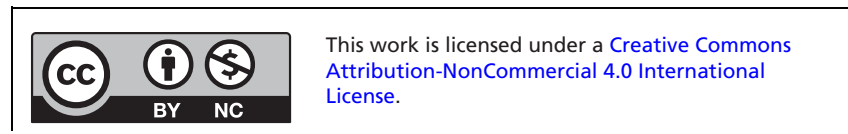


using the SigmaStat (v 11.00) package (SPSS). $P<0.05$ was considered to be statistically significant.

\section{Results}

\section{The level of steroids produced by HFA at the end of first trimester}

We observed that the HFA at the end of the first trimester produced substantial amount of steroids of $\Delta^{5}$ and $\Delta^{4}$ pathways and several $5 \alpha$-and $5 \beta$-reduced metabolites of DHEA and androstenedione (e.g. androstanedione, epiandrosterone, etiocholanolone) as well as some precursors of DHT biosynthesis via the backdoor pathway (e.g. 17OH-DHP and androsterone), but DHT itself was not detected in the HFA at GW9-12 (Fig. 1). The only androgens identified in the HFA were testosterone, which was found in the form of $17 \alpha$ - and $17 \beta$-testosterone and androsterone, a precursor in the biosynthesis of DHT. We also found significant attenuation of the production of reduced steroids, androstanedione and etiocholanolone (by 78 and 92\%, $P<0.001, P<0.01$, respectively) by the HFA at GW11-12 compared to GW9-10 (Fig. 1).

\section{Ontogeny of steroidogenic enzyme expression in the HFA at the end of the first trimester}

Upon exploring the ontogeny of the expression of steroidogenic enzymes and of the ACTH receptor (MC2R) in the HFA at the end of the first trimester as an indication of steroidogenic potential, we found higher level of MC2R
mRNA at GW11-12 then at GW9-10 (by 2.9-fold, $P<0.05$ ), but the expression of its accessory protein MRAP was similar at both ages (Fig. 2A), indicating ongoing differentiation. Similarly, the levels of mRNA encoding steroidogenic genes StAR, CYP11A1 and SULT2A1 were significantly higher in the HFA from GW11-12 then at GW9-10 (Fig. 2A). We also observed that the HFA highly expressed CYP17A1 and genes coding P450 oxidoreductase (POR) and microsomal cytochrome $b_{5}$ (CYB5A) (Fig. 2B), the accessory proteins that support the catalytic activity of CYP17A1.

At the protein level, expression of CYP17A1 was upregulated at GW11-12 compared to GW9-10, while the level of $3 \beta \mathrm{HSD} 2$ protein peaked at GW10 and was later reduced at GW11 (Fig. 3A). Immunohistochemical analysis of cross sections of the HFA revealed expression of several androgen-metabolizing enzymes such as 5 $\alpha$ RI, 5 $\beta$ RI, AKR1C1/AKR1C2 and AKR1C3 (Fig. 3B). This observation agrees well with our finding of several steroidogenic products (e.g. 17OHDHP, androsterone and etiocholanolone) as a result of the activities of these enzymes.

The observed differences in the temporal profiles of the expression of steroidogenic enzymes by the HFA suggest a link between the onset of steroidogenesis and the expression of certain transcription factors.

\section{Expression of transcription factors by the HFA during GW9-12}

To test this suggestion, we characterized the expression of transcription factors involved in both positive and negative regulation of steroidogenic gene expression.
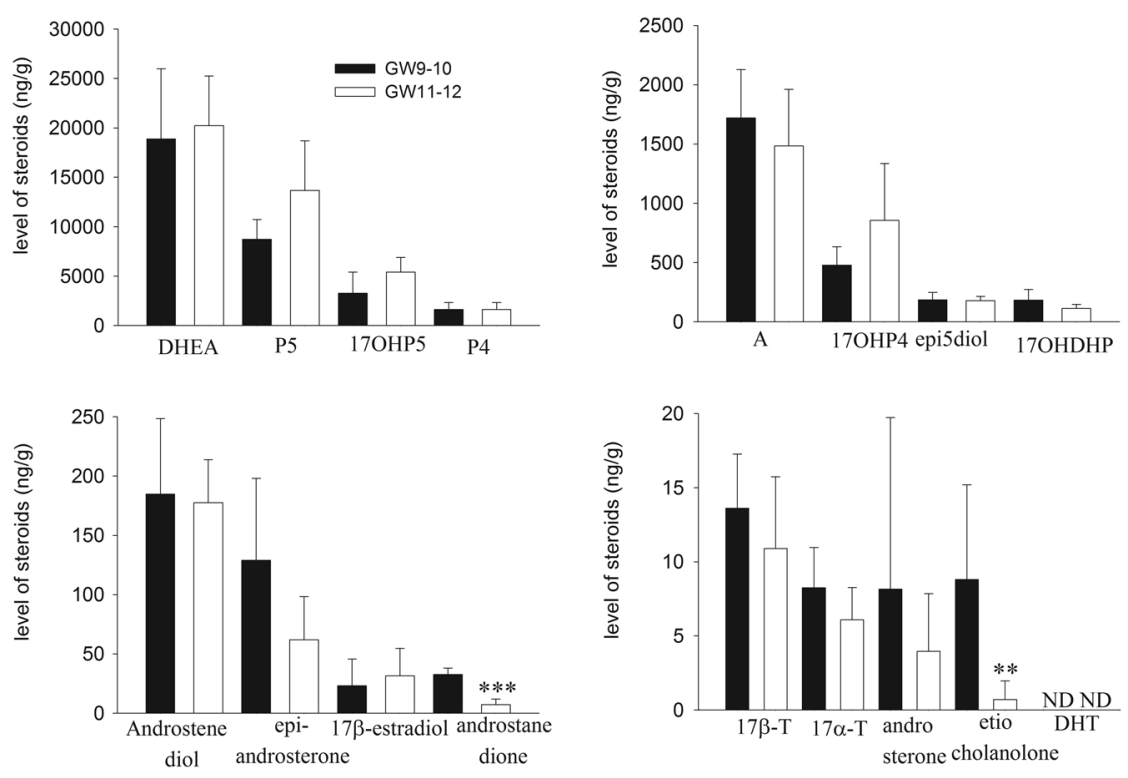

Figure 1

The tissue levels $(\mathrm{ng} / \mathrm{g}$ ) of steroids in the HFA at the end of the first trimester. Concentrations of pregnenolone (5P), 17-OH pregnenolone (17-OHP5), progesterone (P4), 17-OH progesterone (17-OHP4), DHEA, androstenedione (A), $17 \beta$-testosterone (17 $\beta$-T), $17 \alpha$-testosterone $(17 \alpha-\mathrm{T})$, androstenediol, androsterone, $17 \alpha-\mathrm{OH}-$ dihydroprogesterone (17OHDHP), 5-androstene$3 \beta, 17 \alpha$-diol (epi5-diol), epiandrosterone, androstenedione, etiocholanolone, DHT and $17 \beta$-estradiol in the HFA were measured by GC-MS/MS as described in the 'Materials and methods' section. The values shown are means \pm S.D. for five and seven HFA isolated from individual fetuses at GW9-10 and GW11-12, respectively. ${ }^{*} P<0.01,{ }^{*} * P<0.001$ compared to GW9-10. ND, not detectable.

$$
\begin{array}{|lr}
\text { http://www.endocrineconnections.org } & \text { ○ } 2017 \text { The authors } \\
\text { DOI: } 10.1530 / \text { EC-17-0085 } & \text { Published by Bioscientifica Ltd }
\end{array}
$$

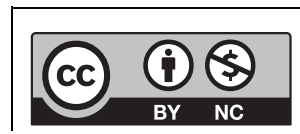

This work is licensed under a Creative Commons Attribution-NonCommercial 4.0 International License. 

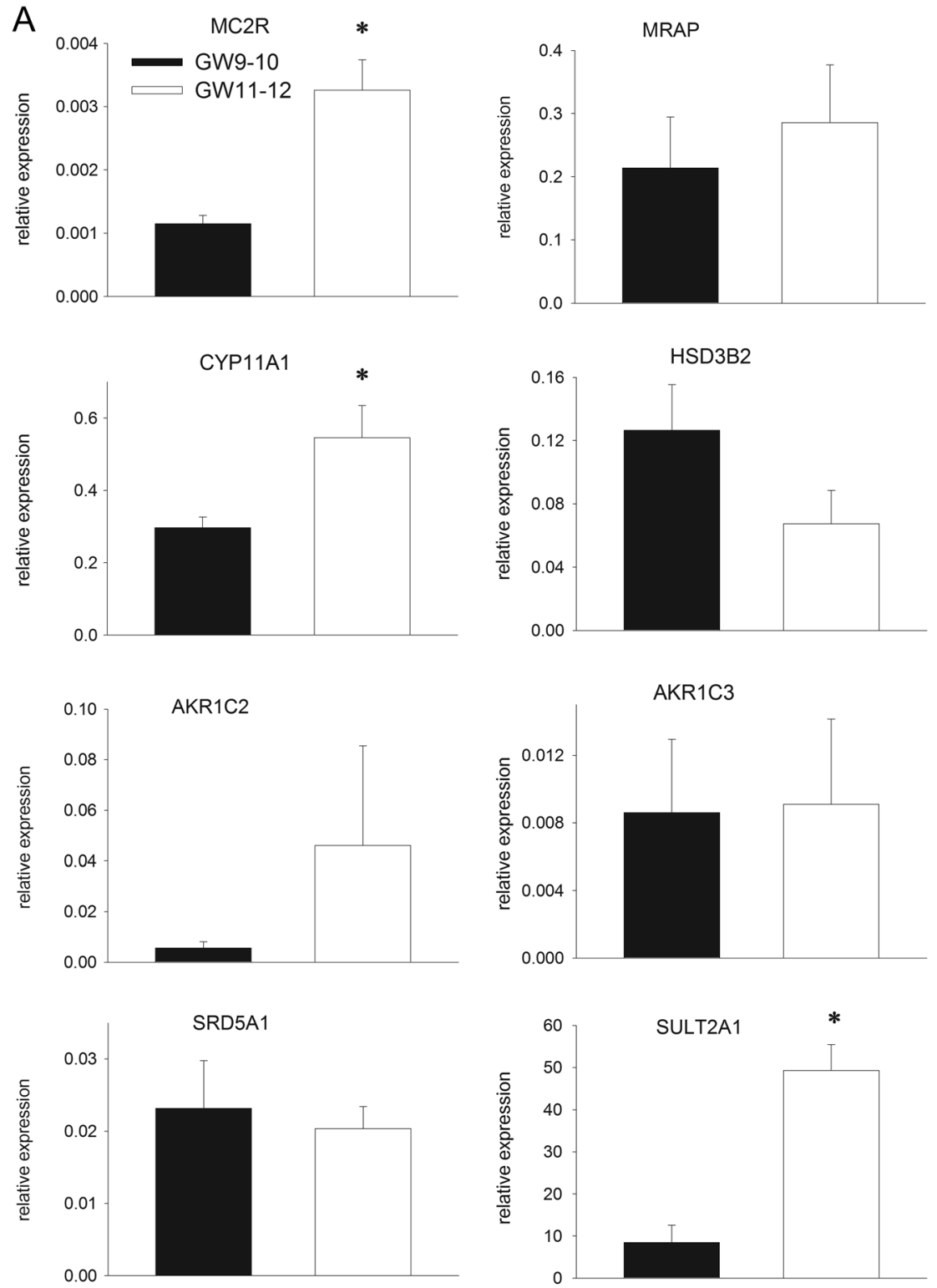

B

CYP17A1

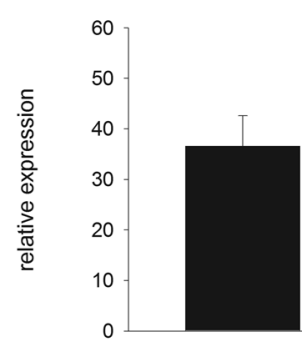

CYB5A

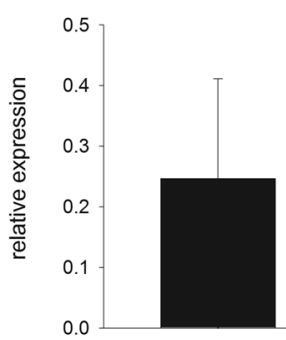

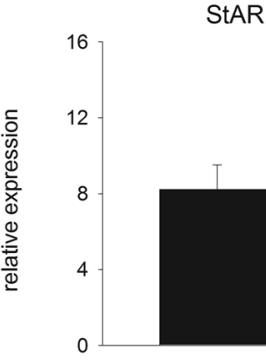
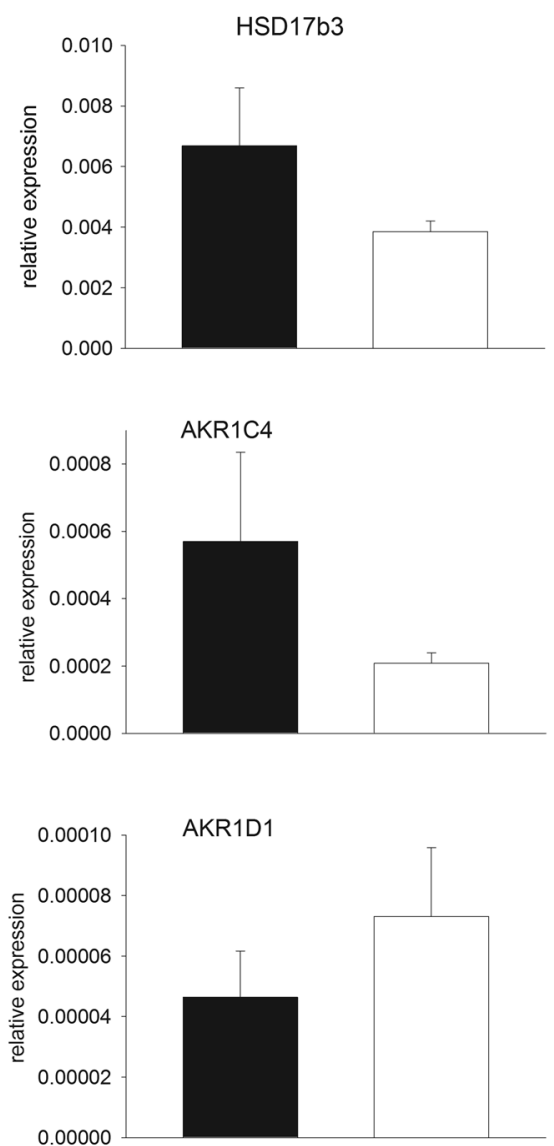

POR

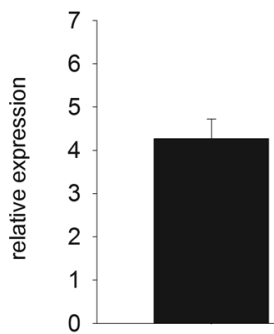

Figure 2

Levels of mRNAs encoding steroidogenic genes in the HFA during GW9-12. The mRNA levels were normalized to GAPDH as a housekeeping gene. The values presented are means \pm S.E. for eight and six HFA at GW9-10 and GW11-12, respectively. * $P<0.05$ compared to GW9-10.

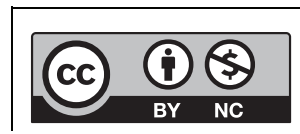

This work is licensed under a Creative Commons Attribution-NonCommercial 4.0 International License. 
A

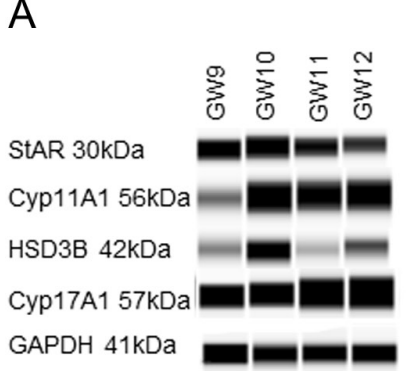

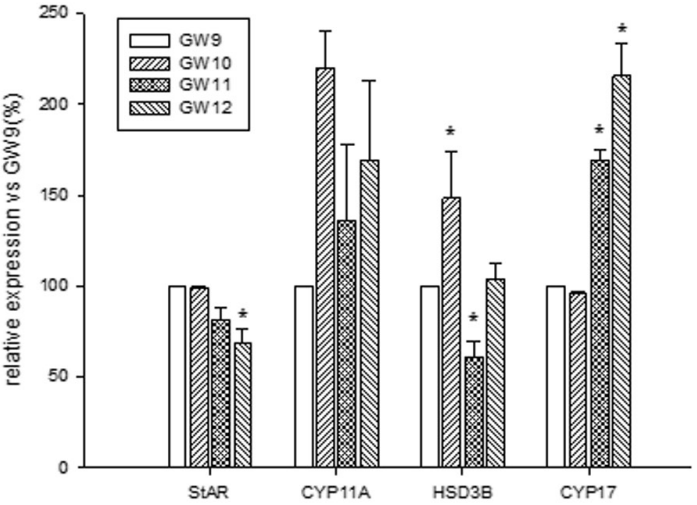

B
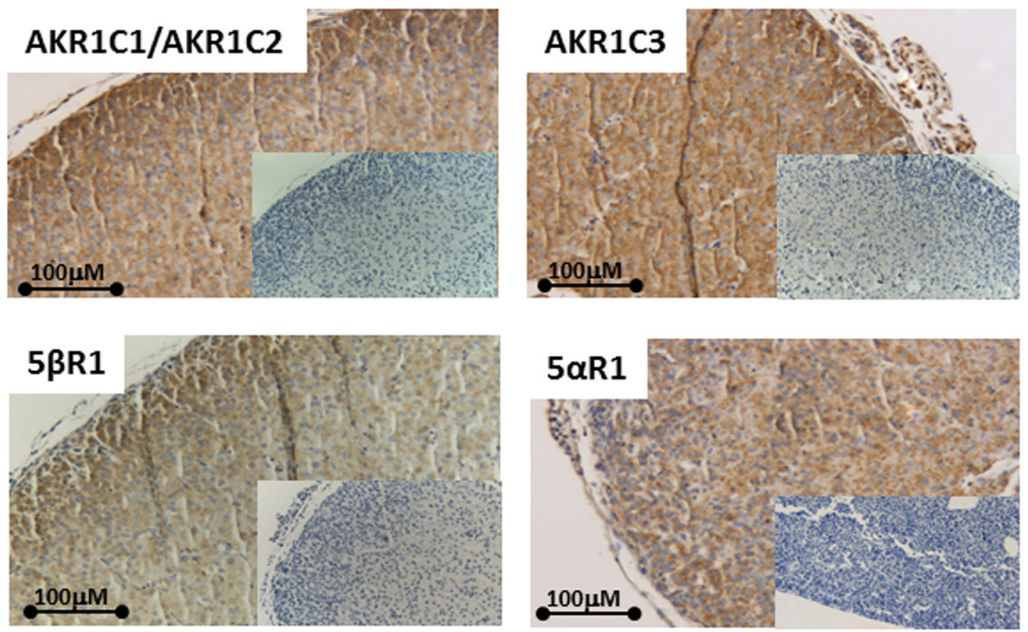

\section{Figure 3}

Expression of steroidogenic enzyme proteins by the HFA during GW9-12. (A). Protein levels were analyzed by Wes-automated Western blotting and representative blots are shown to the left. To the right, band densities are expressed as a percentage of the corresponding density of GW9. The values shown are means \pm S.E. for three (GW9-11) and two (GW12) HFA isolated from individual fetuses. ${ }^{*} P<0.05$ compared to GW9. (B) Expression of androgen-metabolizing enzymes in the HFA at GW10 identified by immunohistochemistry. Inserts show the absence of immunostaining in the presence of nonimmune serum instead of primary antibody. Scale bar: $100 \mu \mathrm{m}$.
We observed that the level of mRNA encoding the transcription factor COUP-TF2 declined significantly in the HFA at GW11-12 and no significant differences in the levels of mRNA encoding the other transcription factors examined were detected in the HFA at GW9-12 (Fig. 4A). However, at the protein level, expression of SF-1 and GATA-6 was significantly upregulated during GW10-12 and GW10-11, while expression of DAX-1 was slightly, but significantly attenuated by GW10 (Fig. 4B).

\section{Discussion}

In the present study, we analyzed the steroidogenic machinery of the HFA during a critical phase of the first trimester, when androgen-dependent sexual dimorphism of the external genitalia is established. To our knowledge, this is the first detailed analysis of steroid production by the HFA at the end of the first trimester employing highly sensitive GC-MS/MS technique and linking this production to the levels of steroidogenic enzymes and related transcription factors. We demonstrated that during GW9-12, HFA produced steroids of the $\Delta^{5}, \Delta^{4}$ and the backdoor pathways of the biosynthesis of DHT, though the latter was limited to production of $17 \alpha-\mathrm{OH}-$ dihydroprogesterone, androsterone and androstanedione without further conversion to DHT. The only androgens identified in the HFA were testosterone and androsterone, a precursor in the biosynthesis of DHT.

Our study has demonstrated that the capacity of the HFA to synthesize testosterone was limited and only less than $1 \%$ of androstenedione was converted to the androgen. This finding agrees well with the study reported that organ culture of the HFA at GW8 can produce low levels of testosterone in unstimulated and activatorstimulated conditions (5). It should also be noted that the abundance of DHEA vs androstenedione and androstenediol compared to testosterone in the HFA is likely associated with low expression of $3 \beta \mathrm{HSD} 2$ reported previously $(5,19)$ and confirmed in the present study.

We also observed for the first time that HFA express $5 \alpha$-reductase 1 (SRD5A1), whose activity is critical for the operation of the backdoor pathway $(8,20$, 21). Similarly, detection of two forms of testosterone,

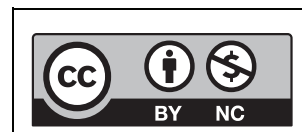

This work is licensed under a Creative Commons Attribution-NonCommercial 4.0 International License. 
A
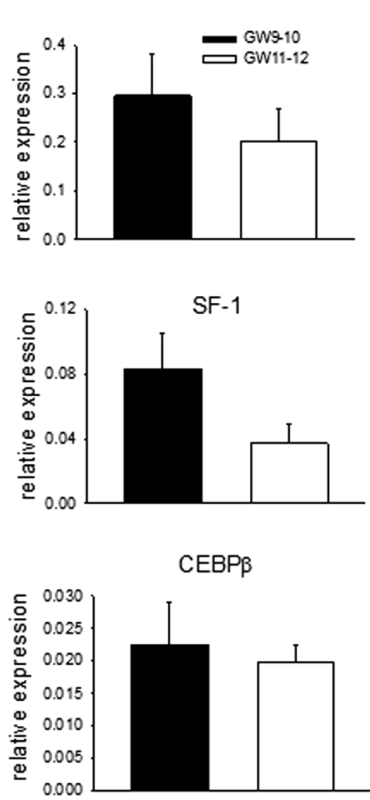

B
COUP-TF2

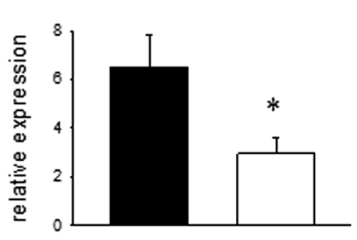

GATA-4

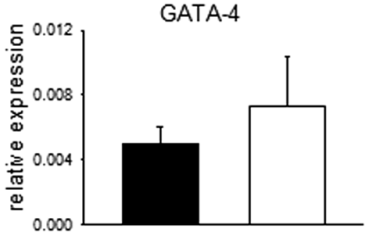

SP-1
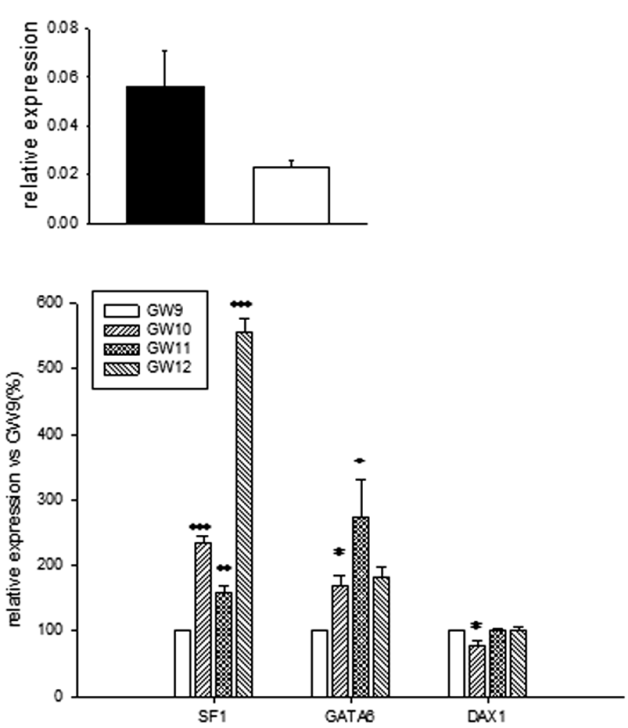

Lhr-1

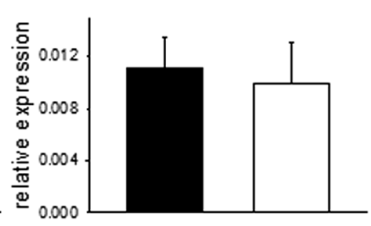

GATA-6

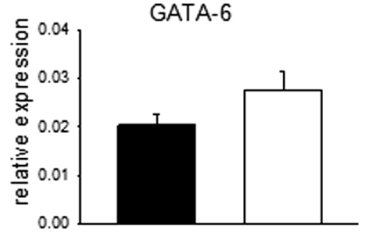

Figure 4

Levels of transcription factors involved in the regulation of steroidogenic enzyme expression in the HFA during GW9-12. (A) The mRNA and (B) protein levels were measured by qPCR and Wes-automated Western blotting, respectively. The values presented are means \pm S.E. for the same number of samples as indicated in Figs 2 and 3. (A) $* P<0.05$ compared to GW9-10, (B) *P<0.05, $* * P<0.01, * * * P<0.001$ compared to GW9.
$17 \alpha$ - and $17 \beta$-testosterone may indicate that the activities of $17 \alpha \mathrm{HSD}, 17 \beta \mathrm{HSD} 3$ and $17 \beta \mathrm{HSD} 5$ were present in the HFA to convert androstenedione to both forms of testosterone as reported previously $(5,13,22)$. Recently, several studies have reported that 11-oxygenated metabolite of testosterone, 11-ketotestosterone (11KT) can be produced by the human adrenals (23), and it has capacity similar to testosterone to bind to the human androgenic receptor (hAR) and regulates AR-dependent gene expression (23, $24,25,26)$, suggesting that androgenic potential of HFA at the end of first trimester cannot be limited to testosterone action only.

In the present study, we observed that the HFA at GW9-12 had capacity to produce androstanedione and androsterone, the precursors in the biosynthesis of DHT $(8,9)$. However, further conversion of these steroids into DHT was blocked in the HFA apparently due to inability of $17 \beta \mathrm{HSD} 3$ to convert androstanedione to DHT and androsterone to androstanediol, which were not detectable in all samples (data not shown). The observed restriction of the HFA to produce potent androgen DHT at the end of the first trimester may play an important role in protection of the developing female external genitalia from deleterious effects of androgens and to avoid their masculinization. However, evidence for the presence of the backdoor pathway in newborn untreated patients with 21-hydroxylase deficiency (21-OHD) suggests that the HFA could contribute to DHT biosynthesis in patients with 21-OHD (12).

It has been reported that androsterone can be synthesized from two steroid precursors, androstanedione and $17 \alpha-\mathrm{OH}$-allopregnanolone by reductive activity of $3 \alpha \mathrm{HSD}$ and the 17-20 lyase activity of CYP17A1, respectively $(8,20)$. We did not detect $17 \alpha-\mathrm{OH}$-allopregnanolone in the HFA but taking into account that this steroid is the most efficient substrate for the 17-20 lyase activity (27), one can suggest that this intermediate steroid was rapidly and effectively

$$
\begin{array}{lr}
\text { http://www.endocrineconnections.org } & \text { ○ } 2017 \text { The authors } \\
\text { DOI: } 10.1530 / \text { EC-17-0085 } & \text { Published by Bioscientifica Ltd }
\end{array}
$$


converted to androsterone by the action of CYP17A1 in the HFA.

Our observation that the expression of MC2R (the receptor for ACTH) in the HFA was elevated during final two weeks of the first trimester may indicate of active differentiation and maturation of the human fetal adrenocortical cells. These findings agree well with an earlier report that the human fetal adrenal cortex is responsive to ACTH and produces corticosteroids and DHEA as early as GW8 $(5,28)$, strongly indicating functional activity of MC2R at early stages of the HFA development.

In the present study, we found that the major steroid produced by the HFA was DHEA, which was associated with high levels of expression of CYP17A1, its accessory proteins, P450 oxidoreductase (POR) and CYB5A. In addition, low level of expression of 3ßHSD2 observed in the $\operatorname{HFA}(5,19)$ may also contribute to excessive production of DHEA. To our knowledge, this is the first time expression of POR and CYB5A by the HFA at the end of the first trimester has been reported. The catalytic activity of CYP17A1 requires a supply of electrons from NADPH via POR $(29,30)$ and its 17,20 -lyase activity is enhanced significantly by microsomal CYB5A $(29,31)$, which supports interactions with POR allosterically (32). Accordingly, our present findings indicate that the CYP17A1-POR-CYB5 complex is fully functional already at early stages of the HFA development. CYP17A1 is expressed exclusively in the fetal zone (FZ), which produces large amounts of DHEA starting from GW7-8 (33), but the biological role of this steroid in the development and maturation of fetal organs during the first trimester is not yet known. In mice, DHEA has been reported to modulate the growth of embryonic neocortical neurons and may thereby play a crucial role in organizing the neocortex (34). Whether this steroid performs a similar function in the human fetus remains to be determined. DHEA has also been shown to be a ligand for many hepatic nuclear receptors and G-protein-coupled receptors (35).

Further, we also demonstrated the elevated expression of SULT2A1 in the HFA at GW11-12 compared to GW9-10, strongly suggesting that this enzyme plays an important role in the regulation of the availability of pregnenolone, 17OH-pregnenolone and DHEA for androgen production by the HFA $(36,37)$. In the human adrenals, SULT2A1 converts pregnenolone, $17 \alpha$-hydroxypregnenolone, DHEA, androsterone and androstenediol to their respective sulfated products $(36,37)$, which are no longer available as substrates for corresponding enzymes (38).
Our current characterization of the expression of steroidogenic enzymes and related transcription factors by the HFA at the end of the first trimester revealed a partial ontogenetical relationship between the levels of transcription factors that promotes steroidogenic gene expression (e.g. SF-1 and GATA6) and of CYP11A1 and CYP17A1. It has been reported that GATA- 6 can work in concert with SF-1 to maximize expression of the enzymes involved in the synthesis of adrenal androgens (39) and can control transcription of CYP17A1 both in a human adrenocortical cell line (40) and virilizing carcinomas (41) as well as is involved in regulating CYP5A transcription (42). Thus, GATA-6 appears to play several roles in connection with development, differentiation and regulation of steroidogenesis in the adrenal cortex (41). Similarly, we observed

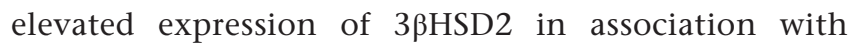
high levels of SF-1 and GATA-6 proteins in the HFA at GW10, while the significant reduction in the level of $3 \beta$ HSD2 at GW11 was not correlated with the decline in the expression of these steroidogenic factors. It was previously demonstrated that nerve growth factor IB (NGFI-B), an orphan nuclear receptor, can regulate the expression of $3 \beta \mathrm{HSD} 2$ in the HFA during the end of the first trimester (5), indicating that SF-1 and GATA-6 may not be primary transcriptional regulators of the expression of this steroidogenic enzyme.

Altogether, our current study demonstrates that the early onset of steroidogenesis in the HFA is characterized by production of steroids of the $\Delta^{5}, \Delta^{4}$ and the backdoor pathways of the biosynthesis of DHT, though the latter was limited to production of $17 \alpha-\mathrm{OH}$-dihydroprogesterone, androsterone and androstanedione without further conversion to DHT. Of those steroids analyzed in the present study, the only potent androgen directly produced by the HFA was testosterone. The similar profiles of the expression of steroidogenic cytochromes and their regulatory transcription factors (e.g. SF-1 and GATA-6) may indicate that these regulatory proteins play a key role in the onset of steroidogenesis in the HFA at a very early stage in their development.

\section{Supplementary data}

This is linked to the online version of the paper at http://dx.doi.org/10.1530/ EC-17-0085.

\section{Declaration of interest}

The authors declare that there is no conflict of interest that could be perceived as prejudicing the impartiality of the research reported.
This work is licensed under a Creative Commons Attribution-NonCommercial 4.0 International License. 
Funding

This work was supported by grant from the European Union's Horizon 2020 research and innovation programme (grant agreement No 634880), the Swedish Research Council, the Children's Cancer Fund, the Frimurare Barnhuset Foundation, Kronprinsessan Lovisas Foundation, the 'Sällskapet Barnavård'; the 'Stiftelsen Sigurd och Elsa Goljes Minne', the 'Stiftelsen Olle Engkvist Byggmästare', the 'Stiftelsen Gunvor och Josef Anérs', the 'Stiftelsen Jane och Dan Olssons' and the 'Stiftelsen Tornspiran'.

\section{References}

1 Ishimoto H \& Jaffe RB. Development and function of the human fetal adrenal cortex: a key component in the feto-placental unit. Endocrine Reviews 201132 317-355. (doi:10.1210/er.2010-0001)

2 Hanley NA, Rainey WE, Wilson DI, Ball SG \& Parker KL. Expression profiles of SF-1, DAX1, and CYP17 in the human fetal adrenal gland: potential interactions in gene regulation. Molecular Endocrinology 2001 15 57-68. (doi:10.1210/mend.15.1.0585)

3 Welsh M, Suzuki H \& Yamada G. The masculinization programming window. Endocrine Development 201427 17-27. (doi:10.1159/000363609)

4 Speiser PW \& White PC. Congenital adrenal hyperplasia due to steroid 21-hydroxylase deficiency. Clinical Endocrinology 199849 411-417. (doi:10.1046/j.1365-2265.1998.00559.x)

5 Goto M, Piper Hanley K, Marcos J, Wood PJ, Wright S, Postle AD, Cameron IT, Mason JI, Wilson DI \& Hanley NA. In humans, early cortisol biosynthesis provides a mechanism to safeguard female sexual development. Journal of Clinical Investigation 2006 116 953-960. (doi:10.1172/JCI25091)

6 Nakamura Y, Hornsby PJ, Casson P, Morimoto R, Satoh F, Xing Y, Kennedy MR, Sasano H \& Rainey WE. Type 5 17 $\beta$-hydroxysteroid dehydrogenase (AKR1C3) contributes to testosterone production in the adrenal reticularis. Journal of Clinical Endocrinology and Metabolism 200994 2192-2198. (doi:10.1210/jc.2008-2374)

7 Wilhelm D \& Koopman P. The makings of maleness: towards an integrated view of male sexual development. Nature Reviews Genetics 20067 620-631. (doi:10.1038/nrg1903)

8 Auchus RJ. The backdoor pathway to dihydrotestosterone. Trends in Endocrinology and Metabolism 200415 432-438. (doi:10.1016/S10432760(04)00214-0)

9 Fukami M, Homma K, Hasegawa T \& Ogata T. Backdoor pathway for dihydrotestosterone biosynthesis: implications for normal and abnormal human sex development. Developmental Dynamics 2013 242 320-329. (doi:10.1002/dvdy.23892)

10 Wilson JD, Auchus RJ, Leihy MW, Guryev OL, Estabrook RW, Osborn SM, Shaw G \& Renfree MB. $5 \alpha$-androstane- $3 \alpha, 17$ beta-diol is formed in tammar wallaby pouch young testes by a pathway involving 5 alphapregnane- $3 \alpha, 17 \alpha$-diol-20-one as a key intermediate. Endocrinology 2003144 575-580. (doi:10.1210/en.2002-220721)

11 Mahendroo M, Wilson JD, Richardson JA \& Auchus RJ. Steroid 5 alpha-reductase 1 promotes $5 \alpha$-androstane- $3 \alpha, 17 \beta$-diol synthesis in immature mouse testes by two pathways. Molecular and Cellular Endocrinology 2004222 113-120. (doi:10.1016/j.mce.2004.04.009)

12 Kamrath C, Hochberg Z, Hartmann MF, Remer T \& Wudy SA. Increased activation of the alternative 'backdoor' pathway in patients with 21-hydroxylase deficiency: evidence from urinary steroid hormone analysis. Journal of Clinical Endocrinology and Metabolism 201297 E367-E375. (doi:10.1210/jc.2011-1997)

13 Fluck CE, Meyer-Boni M, Pandey AV, Kempna P, Miller WL, Schoenle EJ \& Biason-Lauber A. Why boys will be boys: two pathways of fetal testicular androgen biosynthesis are needed for male sexual differentiation. American Journal of Human Genetics 201189 201-218. (doi:10.1016/j.ajhg.2011.06.009)
14 Luu-The V, Belanger A \& Labrie F. Androgen biosynthetic pathways in the human prostate. Best Practice and Research Clinical Endocrinology and Metabolism 200822 207-221. (doi:10.1016/j.beem.2008.01.008)

15 Savchuk I, Morvan ML, Soeborg T, Antignac JP, Gemzell-Danielsson K, Le Bizec B, Soder O \& Svechnikov K. Resveratrol inhibits steroidogenesis in human fetal adrenocortical cells at the end of first trimester. Molecular Nutrition and Food Research 201761 1-8. (doi:10.1002/mnfr.201600522)

16 Evtouchenko L, Studer L, Spenger C, Dreher E \& Seiler RW. A mathematical model for the estimation of human embryonic and fetal age. Cell Transplant 19965 453-464. (doi:10.1016/09636897(96)00079-6)

17 Courant F, Antignac JP, Maume D, Monteau F, Andersson AM, Skakkebaek N, Andre F \& Le Bizec B. Exposure assessment of prepubertal children to steroid endocrine disrupters 1 . Analytical strategy for estrogens measurement in plasma at ultra-trace level. Analytica Chimica Acta 2007586 105-114. (doi:10.1016/j. aca.2006.11.002)

18 Courant F, Aksglaede L, Antignac JP, Monteau F, Sorensen K, Andersson AM, Skakkebaek NE, Juul A \& Le Bizec B. Assessment of circulating sex steroid levels in prepubertal and pubertal boys and girls by a novel ultrasensitive gas chromatography-tandem mass spectrometry method. Journal of Clinical Endocrinology and Metabolism 201095 82-92. (doi:10.1210/jc.2009-1140)

19 Voutilainen R, Ilvesmaki V \& Miettinen PJ. Low expression of 3 betahydroxy-5-ene steroid dehydrogenase gene in human fetal adrenals in vivo; adrenocorticotropin and protein kinase C-dependent regulation in adrenocortical cultures. Journal of Clinical Endocrinology and Metabolism 199172 761-767. (doi:10.1210/jcem-72-4-761)

20 Ghayee HK \& Auchus RJ. Clinical implications of androgen synthesis via 5 $\alpha$-reduced precursors. Endocrine Development 200813 55-66. (doi:10.1159/000134780)

21 Miller WL \& Auchus RJ. The molecular biology, biochemistry, and physiology of human steroidogenesis and its disorders. Endocrine Reviews 201132 81-151. (doi:10.1210/er.2010-0013)

22 Bellemare V, Faucher F, Breton R \& Luu-The V. Characterization of $17 \alpha$-hydroxysteroid dehydrogenase activity (17 $\alpha$-HSD) and its involvement in the biosynthesis of epitestosterone. BMC Biochemistry 20056 12. (doi:10.1186/1471-2091-6-12)

23 Rege J, Nakamura Y, Satoh F, Morimoto R, Kennedy MR, Layman LC, Honma S, Sasano H \& Rainey WE. Liquid chromatography-tandem mass spectrometry analysis of human adrenal vein 19-carbon steroids before and after ACTH stimulation. Journal of Clinical Endocrinology and Metabolism 201398 1182-1188. (doi:10.1210/ jc.2012-2912)

24 Pretorius E, Africander DJ, Vlok M, Perkins MS, Quanson J \& Storbeck KH. 11-Ketotestosterone and 11-ketodihydrotestosterone in castration resistant prostate cancer: potent androgens which can no longer be ignored. PLOS ONE 201611 e0159867. (doi:10.1371/journal. pone.0159867)

25 Pretorius E, Arlt W \& Storbeck KH. A new dawn for androgens: novel lessons from 11-oxygenated C19 steroids. Molecular and Cellular Endocrinology 2016441 76-85. (doi:10.1016/j.mce.2016.08.014)

26 Turcu AF, Nanba AT, Chomic R, Upadhyay SK, Giordano TJ, Shields JJ, Merke DP, Rainey WE \& Auchus RJ. Adrenal-derived 11-oxygenated 19-carbon steroids are the dominant androgens in classic 21-hydroxylase deficiency. European Journal of Endocrinology 2016174 601-609. (doi:10.1530/EJE-15-1181)

27 Gupta MK, Guryev OL \& Auchus RJ. 5 $\alpha$-reduced C21 steroids are substrates for human cytochrome P450c17. Archives of Biochemistry and Biophysics 2003418 151-160. (doi:10.1016/j.abb.2003.07.003)

28 Seron-Ferre M, Lawrence CC, Siiteri PK \& Jaffe RB. Steroid production by definitive and fetal zones of the human fetal adrenal gland. Journal of Clinical Endocrinology and Metabolism 197847 603-609. (doi:10.1210/jcem-47-3-603)

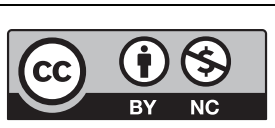

This work is licensed under a Creative Commons Attribution-NonCommercial 4.0 International License. 
29 Miller WL, Auchus RJ \& Geller DH. The regulation of 17,20 lyase activity. Steroids 199762 133-142. (doi:10.1016/S0039128X(96)00172-9)

30 Miller WL, Geller DH \& Auchus RJ. The molecular basis of isolated 17,20 lyase deficiency. Endocrine Research 199824 817-825. (doi:10.3109/07435809809032692)

31 Katagiri M, Kagawa N \& Waterman MR. The role of cytochrome b5 in the biosynthesis of androgens by human P450c17. Archives of Biochemistry and Biophysics 1995317 343-347. (doi:10.1006/abbi.1995.1173)

32 Auchus RJ, Lee TC \& Miller WL. Cytochrome b5 augments the 17,20lyase activity of human P450c17 without direct electron transfer. Journal of Biological Chemistry 1998273 3158-3165. (doi:10.1074/jbc.273.6.3158)

33 Mesiano S \& Jaffe RB. Developmental and functional biology of the primate fetal adrenal cortex. Endocrine Reviews 199718 378-403. (doi:10.1210/er.18.3.378)

34 Compagnone NA \& Mellon SH. Dehydroepiandrosterone: a potential signalling molecule for neocortical organization during development. PNAS 199895 4678-4683. (doi:10.1073/pnas.95.8.4678)

35 Prough RA, Clark BJ \& Klinge CM. Novel mechanisms for DHEA action. Journal of Molecular Endocrinology 201656 R139-R155. (doi:10.1530/JME-16-0013)

36 Strott CA. Steroid sulfotransferases. Endocrine Reviews 199617 670-697. (doi:10.1210/edrv-17-6-670)
37 Weinshilboum RM, Otterness DM, Aksoy IA, Wood TC, Her C \& Raftogianis RB. Sulfation and sulfotransferases 1: sulfotransferase molecular biology: cDNAs and genes. FASEB Journal 199711 3-14.

38 Rainey WE, Carr BR, Sasano H, Suzuki T \& Mason JI. Dissecting human adrenal androgen production. Trends in Endocrinology and Metabolism 200213 234-239. (doi:10.1016/S1043-2760(02)00609-4)

39 Jimenez P, Saner K, Mayhew B \& Rainey WE. GATA-6 is expressed in the human adrenal and regulates transcription of genes required for adrenal androgen biosynthesis. Endocrinology 2003144 4285-4288. (doi:10.1210/en.2003-0472)

40 Fluck CE \& Miller WL. GATA-4 and GATA-6 modulate tissue-specific transcription of the human gene for P450c17 by direct interaction with Sp1. Molecular Endocrinology 200418 1144-1157. (doi:10.1210/ me.2003-0342)

41 Kiiveri S, Liu J, Arola J, Heikkila P, Kuulasmaa T, Lehtonen E, Voutilainen R \& Heikinheimo M. Transcription factors GATA-6, SF-1, and cell proliferation in human adrenocortical tumors. Molecular and Cellular Endocrinology 2005233 47-56. (doi:10.1016/j. mce.2005.01.012)

42 Huang N, Dardis A \& Miller WL. Regulation of cytochrome b5 gene transcription by Sp3, GATA-6, and steroidogenic factor 1 in human adrenal NCI-H295A cells. Molecular Endocrinology 200519 2020-2034. (doi:10.1210/me.2004-0411)

Received in final form 31 May 2017

Accepted 6 June 2017

Accepted Preprint published online 7 June 2017 http://www.endocrineconnections.org DOI: 10.1530/EC-17-0085 (c) 2017 The authors Published by Bioscientifica Ltd

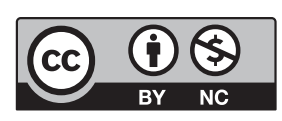

This work is licensed under a Creative Commons Attribution-NonCommercial 4.0 International License. 